Article

\title{
Controllability Comparison of the Four-Product Petlyuk Dividing Wall Distillation Column Using Temperature Control Schemes
}

\author{
Xing Qian ${ }^{\mathbb{D}}$, Rui Liu, Kejin Huang *, Haisheng Chen, Yang Yuan, Liang Zhang and \\ Shaofeng Wang \\ College of Information Science and Technology, Beijing University of Chemical Technology, Beijing 100029, \\ China; qianx@mail.buct.edu.cn (X.Q.); 2017310228@mail.buct.edu.cn (R.L.); chenhs@mail.buct.edu.cn (H.C.); \\ yuanyang@mail.buct.edu.cn (Y.Y.); zhangl@mail.buct.edu.cn (L.Z.); sfwang@mail.buct.edu.cn (S.W.) \\ * Correspondence: huangkj@mail.buct.edu.cn
}

Received: 9 December 2019; Accepted: 14 January 2020; Published: 16 January 2020

\begin{abstract}
An effective process intensification strategy based on dividing walls shows promising energy-saving results for distillation processes. The three-product Petlyuk dividing wall distillation columns (DWDCs) are able to save approximately 30\% energy in comparison with the traditional distillation columns. Furthermore, the four-product extended Petlyuk DWDC reduces about 50\% of operation costs than conventional distillation sequences. Although researchers have extensively studied control schemes for the three-product Petlyuk DWDC, relatively little work has been done on the four-product extended Petlyuk DWDC. This paper studies feasible temperature control schemes containing temperature control scheme (TC), simplified temperature difference control scheme (STDC), and simplified double temperature difference control scheme (SDTDC) for the four-product extended Petlyuk DWDC. STDC and SDTDC are introduced so as to improve the dynamic performances with simple control schemes. All three control schemes are tested against a series of feed compositions and feed rate disturbances. Dynamic performances prove that the proposed STDC and SDTDC schemes are better at handling the inserted feed disturbances. These are very encouraging results for industrialization of the four-product extended Petlyuk DWDC in the future.
\end{abstract}

Keywords: dividing wall distillation column (DWDC); extended Petlyuk DWDC; temperature control (TC); simplified temperature difference control (STDC); simplified double temperature difference control (SDTDC)

\section{Introduction}

Dividing wall distillation columns (DWDCs) are effective process intensification strategies that require significantly reduced operation costs and capital costs [1,2]. While the three-product Petlyuk DWDC is able to reduce approximately $30 \%$ of operation costs [3], the four-product extended Petlyuk DWDC can save about $50 \%$ of operation costs [4]. Though the energy saving ability of DWDC is very considerable, the controllability of the DWDC is very complicated due to excessive loop interactions and highly nonlinear behaviors.

Scholars and researchers have investigated the controllability concerning different configurations of DWDC. Wolff and Skogestad [5] proposed a three-point control scheme and a four-point control scheme to hold the purities of the three-product streams of the Petlyuk DWDC. However, the Petlyuk DWDC with four compositions specified may display complicated behaviors and infeasible operating areas. Therefore, the synthesis and design of the Petlyuk DWDC should avoid specification for the two side stream impurities independently. Wang and Wong [6] investigated the three-product Petlyuk DWDC and pointed out that 
trade-off exists between the controllability and the energy saving ability. A composition and temperature cascaded control structure was then proposed in order to stabilize the DWDC and save the energy cost. Ling and Luyben [7] investigated a new composition control scheme with an additional control loop, besides the three composition control loops, controlling the three-product purities through manipulating vapor boilup, side product rate, and reflux rate. The additional loop controlled the heaviest component fraction in the overhead vapor of the prefractionator and implicitly minimized energy consumption. They [8] further recommended a four-point TC scheme and a four-point TDC scheme. Skogestad et al. [9,10] studied both the three-product and the four-product extended Petlyuk DWDC, and proposed feasible composition control schemes and cascade control schemes. Qian et al. [11,12] studied practicable control schemes containing temperature control scheme and cascade control scheme using proportional integral (PI) controllers and model predictive control (MPC) to regulate the four-product Kaibel DWDC.

Researchers have thoroughly investigated control schemes for the three-product Petlyuk DWDC, but relatively few investigations have been done on the four-product extended Petlyuk DWDC. This extended Petlyuk DWDC has extremely complicated topology structure. This feature unavoidably causes highly nonlinear behaviors and excessive loop interactions, which is more difficult to operate and control than the three-product Petlyuk DWDC. This paper proposes temperature control scheme (TC), simplified temperature difference control scheme (STDC), and simplified double temperature difference control scheme (SDTDC) for the four-product extended Petlyuk DWDC to separate a liquid alcohol mixture. The proposed control schemes are tested against a series of feed composition and feed flow disturbances. Dynamic responses are compared and discussed according to the control schemes dynamic performances.

\section{Synthesis and Design}

The four-product extended Petlyuk DWDC is used for fractionating a liquid feed containing methanol, ethanol, 1-propanol, and n-butanol (represented as A, B, C, and D, respectively) with $1 \mathrm{kmol} / \mathrm{h}$ feed flow rate. The fresh feed is saturated liquid, with each component being $25 \%$ (mole fraction). The NRTL (Non-Random Two-Liquid) equation is employed as the property method. The database of Aspen Physical Property System offers a variety of vapor-liquid equilibrium and liquid-liquid equilibrium binary parameters based on regression of experimental data and literature data.

The extended Petlyuk DWDC, as illustrated in Figure 1, is able to be implemented in industry; however, the steady-state and dynamic simulations employ the thermodynamically equivalent configuration, as shown in Figure 2. The prefractionator carries out a sharp A/D split, the middle section performs a sharp A/C split and a sharp B/D split, while the main section completes a sharp A/B split, a sharp B/C split, and a sharp C/D split. P is short for the prefractionator. MI stands for the middle section. MA indicates for the main section. The molar composition specifications of the four product streams are all 99\%. The detailed data of the synthesis of the extended Petlyuk DWDC are illustrated in Figure 3, including the flow rates, compositions, pressures, and temperatures of the feed and product streams.

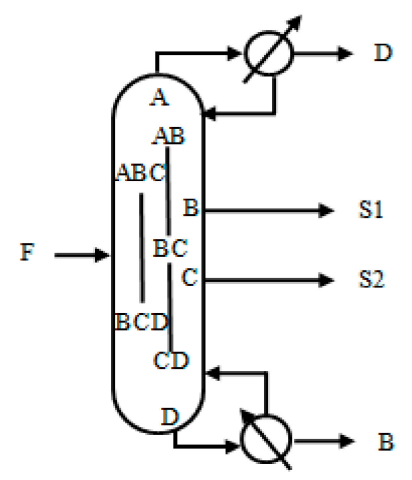

Figure 1. The extended Petlyuk dividing wall distillation column (DWDC). 


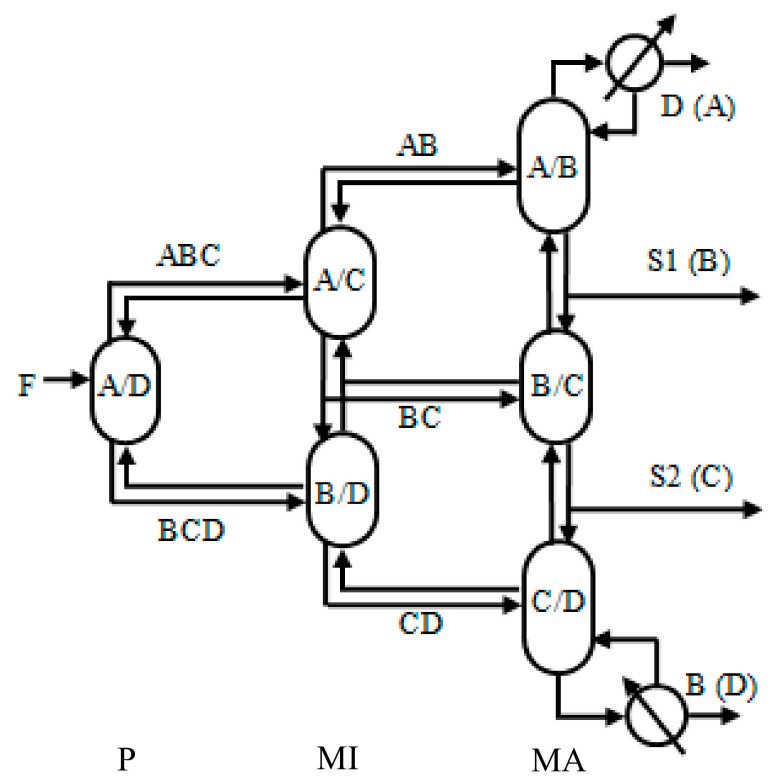

Figure 2. Thermally coupled structure of the extended Petlyuk DWDC.

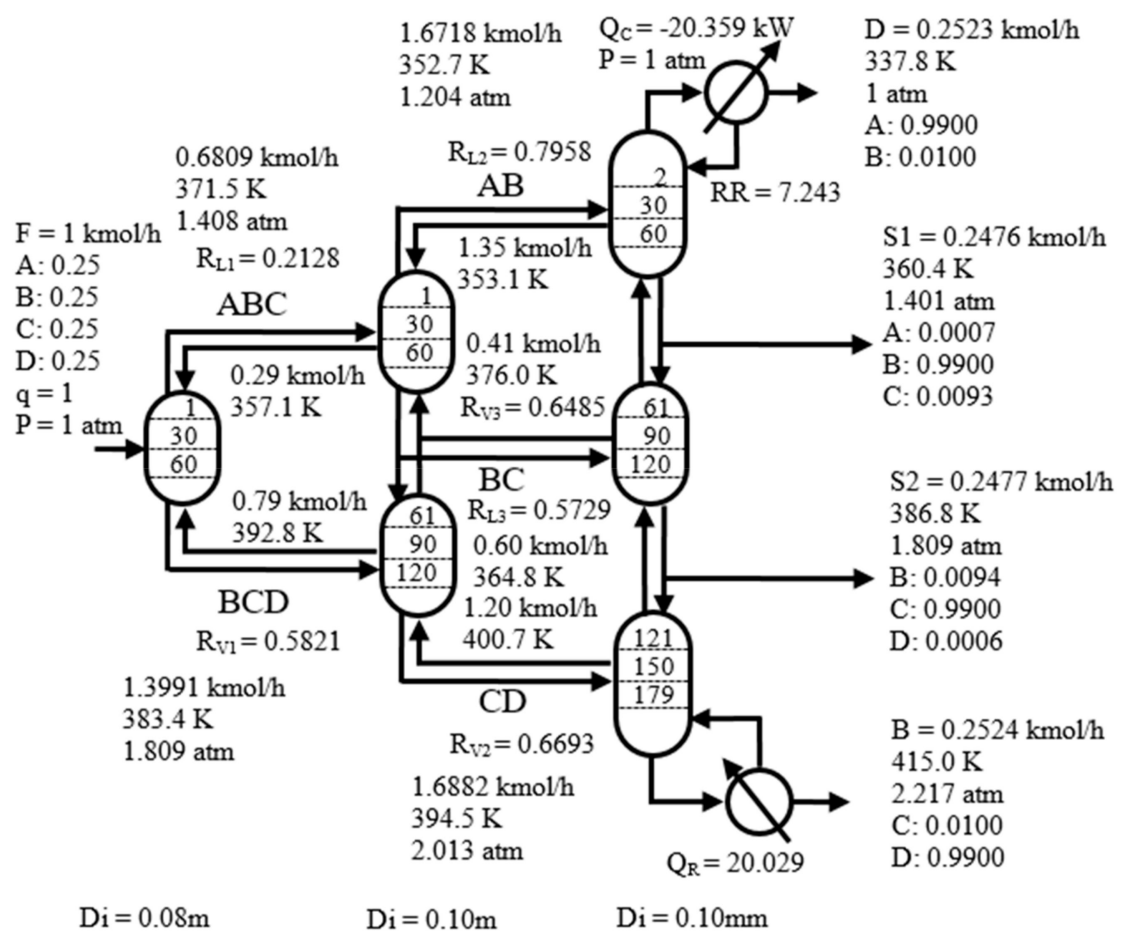

Figure 3. The detailed data of the four-product extended Petlyuk DWDC.

\section{Control Schemes}

TC, STDC, and SDTDC for the four-product extended Petlyuk DWDC are investigated in this work. Pure temperature control (without composition control) is applied in this paper so as to be more applicable in industries. The pressure of the Petlyuk DWDC is regulated through the condenser duty. The liquid levels of the sump and reflux drum are regulated by the column bottom product rate and reflux rate, respectively. For level and pressure controllers, their gains and integral times employ suggested values in the open literature [13]. The size of the distillation column is determined using Tray Sizing in Aspen Plus, while the sizes of the reflux drum and sump of the distillation column are both set based on 10 min holdup at half liquid level [13]. 
Ten manipulated variables are available besides those used for the level controllers and pressure controller:

1. Liquid reflux stream from MI to P (L1)

2. Vapor boilup stream from MI to P (V1)

3. Liquid reflux stream from MA to MI (L2)

4. Vapor boilup stream from MA to MI (V2)

5. Liquid reflux stream from MI to MA (L3)

6. Vapor boilup stream from MA to MI (V3)

7. Reboiler duty of $\mathrm{MA}\left(\mathrm{Q}_{\mathrm{R}}\right)$

8. Distillate stream flow rate of MA (D)

9. First side stream flow rate of MA (S1)

10. Second side stream flow rate of MA (S2).

As vapor splits are usually difficult to manipulate in chemical industries, three vapor splits are constant so as to be more applicable in industry. Therefore, six available manipulated variables remain in this study. The feed forward control $\left(Q_{R} / F\right)$ is used in the proposed control schemes.

In order to determine the sensitive tray temperatures, sensitivity analysis is employed, as shown in Figure 4 . For each available manipulated variable, $+0.1 \%$ change is added one at a time to achieve the corresponding sensitive tray temperatures. So as to select the reference and sensitive tray temperatures for STDC and SDTDC, singular value decomposition is used, as shown in Figures 5 and 6, respectively.

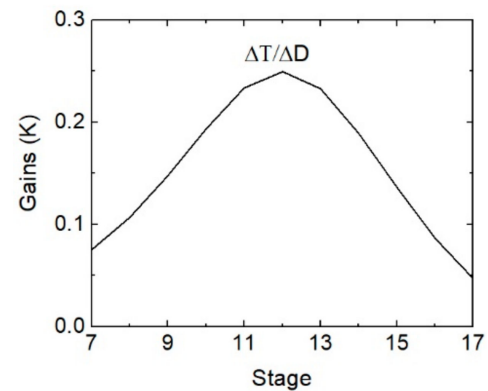

(a) D

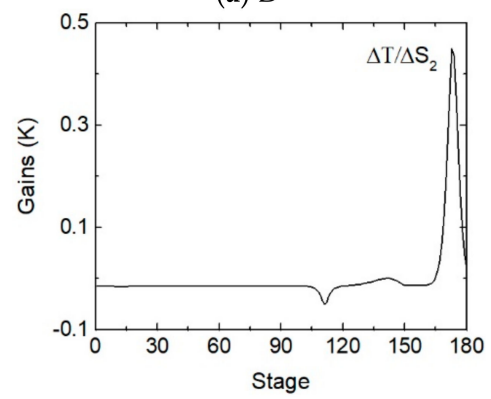

(c) S2

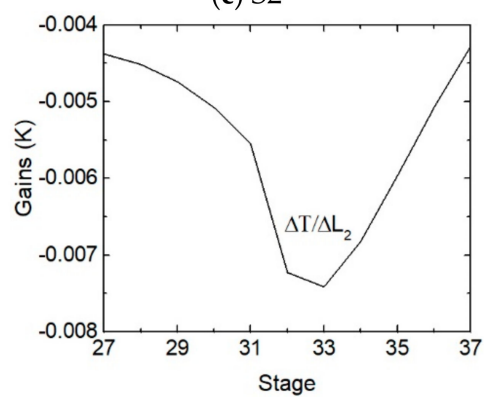

(e) L2

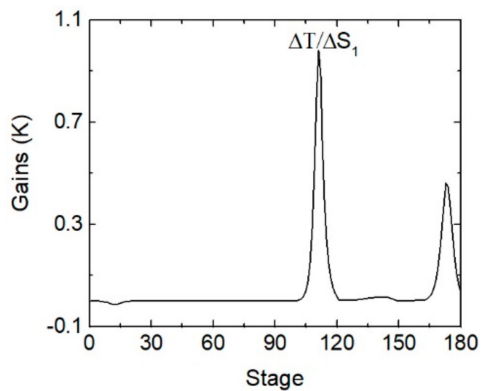

(b) $\mathrm{S1}$

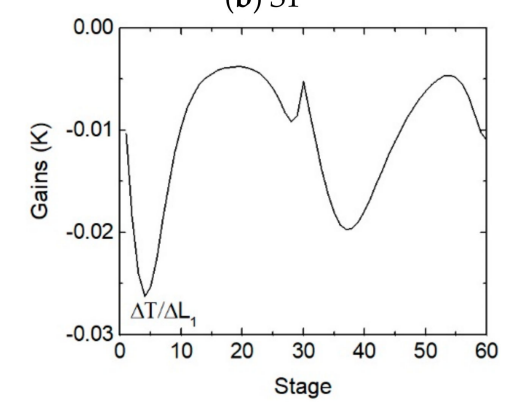

(d) L1

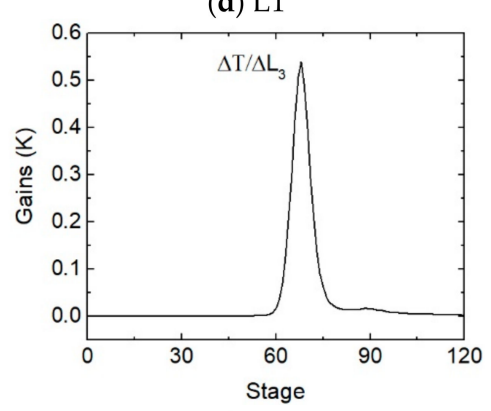

(f) L3

Figure 4. Sensitivity analysis profiles: (a) D; (b) S1; (c) S2; (d) L1; (e) L2; (f) L3. 


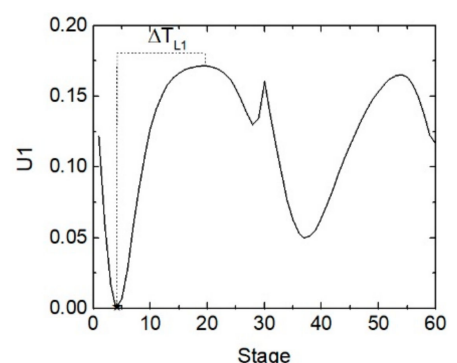

(a) L1

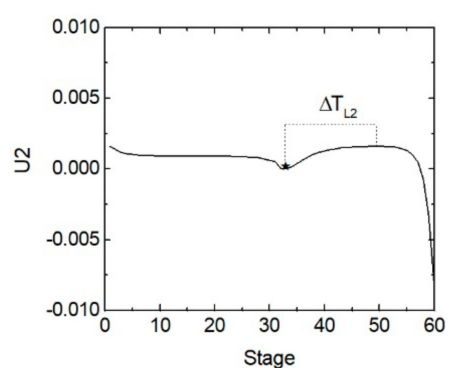

(b) L2

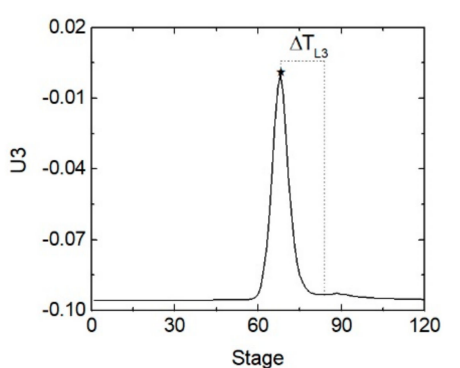

(c) L3

Figure 5. Singular value decomposition analysis profiles for the simplified temperature difference control scheme (STDC): (a) L1; (b) L2; (c) L3.

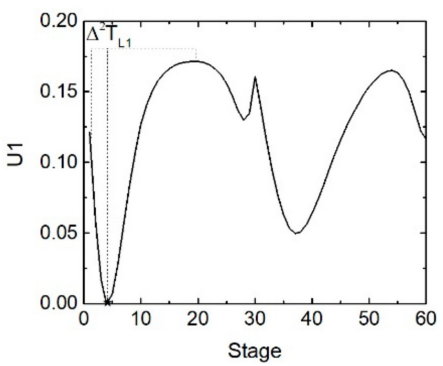

(a) L1

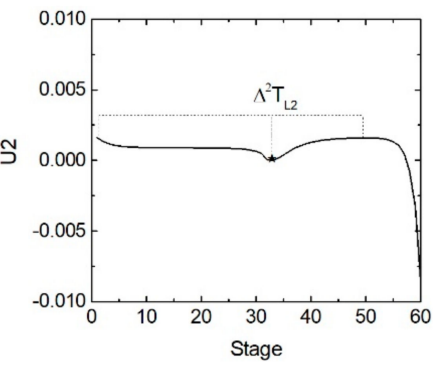

(b) L2

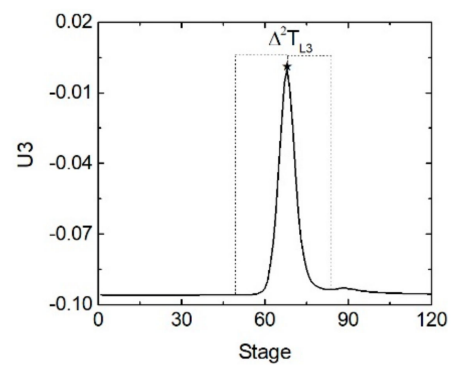

(c) L3

Figure 6. Singular value decomposition analysis profiles for simplified double temperature difference control scheme (SDTDC): (a) L1; (b) L2; (c) L3.

There are six controlled temperatures, as shown in Figure 4. There is one sensitive temperature (the 4th tray) in the prefractionator, two sensitive temperatures (the 33rd and 68th trays) in the middle section, and three sensitive temperatures (the 12th, $111^{\text {th }}$, and 173rd trays) in the main section. Therefore, the sensitive temperatures to be controlled are $\left[\mathrm{T}_{\mathrm{P}, 4}, \mathrm{~T}_{\mathrm{MI}, 33}, \mathrm{~T}_{\mathrm{MI}, 68}, \mathrm{~T}_{\mathrm{MA}, 12}, \mathrm{~T}_{\mathrm{MA}, 111}, \mathrm{~T}_{\mathrm{MA}, 173}\right]$. According to the "pair close rule", the manipulated variables should be close to the controlled variables. Therefore, L1 is adopted to regulate the sensitive temperature in the prefractionator; L2 and L3 are employed to regulate two sensitive temperatures in the middle section; D, S1, and S2 are selected to regulate three sensitive temperatures in the main section. For stabilizing control, at least one TC loop should be employed to separate one split of the distillation column [14]. As the complicated four-product extended Petlyuk DWDC inherently has highly nonlinear behaviors and excessive loop interactions, it is of significance to decrease the excessive interactions between the control loops with simpler control schemes. The prefractionator completes one sharp split and one temperature controller is needed. The middle section carries out two sharp splits and requires two temperature controllers. Three sharp splits are performed in the main section and three temperature controllers are required.

There are adjacent component sharp splits in the main section, so the controlled sensitive temperatures indicate the product compositions relatively properly. However, the sharp splits in the middle section and prefractionator are not between adjacent components; besides, distributed components exist at both top and bottom streams of the middle section and prefractionator. Therefore, the controlled sensitive temperatures indicate the product compositions relatively improperly. Yu and Luyben [15] recommended the adoption of several temperatures in the multicomponent distillations. In this paper, STDC and SDTDC are proposed to solve this problem. In the STDC scheme, TDC is used in the middle section and prefractionator, while TC is employed in the main section. The controlled temperature differences are the TD between the 19th and 4th tray in the prefractionator, the TD between the 50th and 33rd tray and the TD between the 84th and 68th tray in the middle section. In summary, the controlled variables in the STDC scheme are $\left[T_{P, 19}-T_{P, 4}, T_{M I, 50}-T_{M I, 33}, T_{M I, 84}-T_{M I, 68}, T_{M A, 12}\right.$, $\left.\mathrm{T}_{\mathrm{MA}, 111}, \mathrm{~T}_{\mathrm{MA}, 173}\right]$. In the SDTDC scheme, DTDC is adopted in the middle section and prefractionator, while TC is implemented in the main section. The controlled double temperature differences (DTDs) 
are the DTD $\left[\left(\mathrm{T}_{\mathrm{P}, 19}-\mathrm{T}_{\mathrm{P}, 4}\right)-\left(\mathrm{T}_{\mathrm{P}, 4}-\mathrm{T}_{\mathrm{P}, 2}\right)\right]$ in the prefractionator, and the DTDs $\left[\left(\mathrm{T}_{\mathrm{MI}, 50}-\mathrm{T}_{\mathrm{MI}, 33}\right)-\right.$ $\left.\left(\mathrm{T}_{\mathrm{MI}, 33}-\mathrm{T}_{\mathrm{MI}, 2}\right),\left(\mathrm{T}_{\mathrm{MI}, 84}-\mathrm{T}_{\mathrm{MI}, 68}\right)-\left(\mathrm{T}_{\mathrm{MI}, 68}-\mathrm{T}_{\mathrm{MI}, 50}\right)\right]$ in the middle section. In summary, the controlled variables in the SDTDC scheme are $\left[\left(\mathrm{T}_{\mathrm{P}, 19}-\mathrm{T}_{\mathrm{P}, 4}\right)-\left(\mathrm{T}_{\mathrm{P}, 4}-\mathrm{T}_{\mathrm{P}, 2}\right),\left(\mathrm{T}_{\mathrm{MI}, 50}-\mathrm{T}_{\mathrm{MI}, 33}\right)-\left(\mathrm{T}_{\mathrm{MI}, 33}-\mathrm{T}_{\mathrm{MI}, 2}\right)\right.$, $\left.\left(\mathrm{T}_{\mathrm{MI}, 84}-\mathrm{T}_{\mathrm{MI}, 68}\right)-\left(\mathrm{T}_{\mathrm{MI}, 68}-\mathrm{T}_{\mathrm{MI}, 50}\right)\right]$.

\subsection{Temperature Control (TC) Scheme}

TC scheme contains four temperature controllers, as shown in Figure 7. For the controller TC1, the controlled variable is $\mathrm{T}_{\mathrm{P}, 4}$ and the manipulated variable is liquid reflux from MI to $\mathrm{P}$ (L1). The liquid reflux from MA to MI (L2) and the liquid reflux from MI to MA (L3) are adopted to control the 33rd and 68th tray temperatures in the middle section, respectively. D, S1, and S2 of the main section are employed to regulate the 12th tray, 111th tray, and 173rd tray temperatures, respectively.

The Tyreus-Luyben tuning method is adopted for calculating the gains and integral times of temperature controllers. The controller values of the TC scheme are illustrated in Table 1.

Table 1. Controller values.

\begin{tabular}{|c|c|c|c|c|c|}
\hline Schemes & Loop & MV & $\mathrm{CV}$ & Gain & Integral Time (min) \\
\hline \multirow[t]{6}{*}{ TC } & TC1 & L1 & $\mathrm{T}_{\mathrm{P}, 4}$ & 8.26 & 17.16 \\
\hline & TC2 & $\mathrm{L} 2$ & $\mathrm{~T}_{\mathrm{MI}, 33}$ & 5.43 & 15.84 \\
\hline & TC3 & L3 & $\mathrm{T}_{\mathrm{MI}, 68}$ & 3.94 & 14.52 \\
\hline & TC4 & $\mathrm{D}$ & $\mathrm{T}_{\mathrm{MA}, 12}$ & 10.26 & 43.56 \\
\hline & TC5 & S1 & $\mathrm{T}_{\mathrm{MA}, 111}$ & 2.24 & 30.36 \\
\hline & TC6 & S2 & $\mathrm{T}_{\mathrm{MA}, 173}$ & 3.98 & 21.12 \\
\hline \multirow[t]{6}{*}{ STDC } & TDC1 & L1 & $\mathrm{T}_{\mathrm{P}, 19}-\mathrm{T}_{\mathrm{P}, 4}$ & 0.697 & 14.52 \\
\hline & TDC2 & L2 & $\mathrm{T}_{\mathrm{MI}, 50}-\mathrm{T}_{\mathrm{MI}, 33}$ & 0.365 & 14.52 \\
\hline & TDC3 & L3 & $\mathrm{T}_{\mathrm{MI}, 84}-\mathrm{T}_{\mathrm{MI}, 68}$ & 0.228 & 15.84 \\
\hline & TC4 & $\mathrm{D}$ & $\mathrm{T}_{\mathrm{MA}, 12}$ & 12.82 & 44.88 \\
\hline & TC5 & S1 & $\mathrm{T}_{\mathrm{MA}, 111}$ & 2.25 & 30.36 \\
\hline & TC6 & $\mathrm{S} 2$ & $\mathrm{~T}_{\mathrm{MA}, 173}$ & 3.62 & 21.12 \\
\hline \multirow[t]{6}{*}{ SDTDC } & DTDC1 & L1 & $\left(\mathrm{T}_{\mathrm{P}, 19}-\mathrm{T}_{\mathrm{P}, 4}\right)-\left(\mathrm{T}_{\mathrm{P}, 4}-\mathrm{T}_{\mathrm{P}, 2}\right)$ & 0.881 & 13.20 \\
\hline & DTDC2 & $\mathrm{L} 2$ & $\left(\mathrm{~T}_{\mathrm{MI}, 50}-\mathrm{T}_{\mathrm{MI}, 33}\right)-\left(\mathrm{T}_{\mathrm{MI}, 33}-\mathrm{T}_{\mathrm{MI}, 2}\right)$ & 0.213 & 13.20 \\
\hline & DTDC3 & L3 & $\left(\mathrm{T}_{\mathrm{MI}, 84}-\mathrm{T}_{\mathrm{MI}, 68}\right)-\left(\mathrm{T}_{\mathrm{MI}, 68}-\mathrm{T}_{\mathrm{MI}, 50}\right)$ & 0.027 & 15.84 \\
\hline & TC4 & $\mathrm{D}$ & $\mathrm{T}_{\mathrm{MA}, 12}$ & 10.53 & 42.24 \\
\hline & TC5 & S1 & $\mathrm{T}_{\mathrm{MA}, 111}$ & 3.29 & 23.76 \\
\hline & TC6 & S2 & $\mathrm{T}_{\mathrm{MA}, 173}$ & 4.87 & 14.52 \\
\hline
\end{tabular}

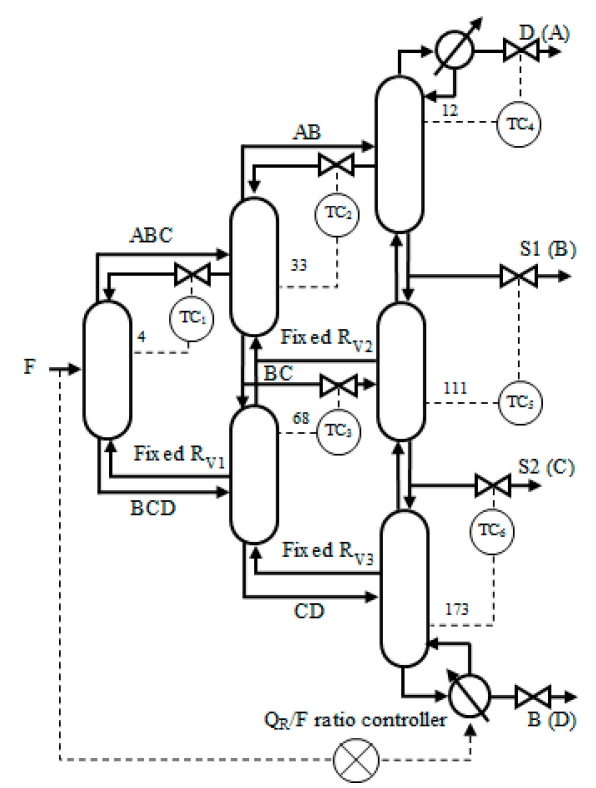

Figure 7. Temperature control (TC) scheme. 


\subsection{Simplified Temperature Difference Control Scheme (STDC)}

Small changes in column pressure may severely affect the dynamic performances of temperature control. Especially in the multicomponent distillation columns, the controlled sensitive temperatures may not accord with the compositions and indicate the compositions relatively improperly. In consideration of improving the dynamic performances, the STDC scheme, as illustrated in Figure 8, is introduced.

In the STDC scheme, three temperature controllers in the main section are the same, while three temperature difference controllers in the former two sections are different from the TC scheme. L1 is employed as the manipulated variable to regulate the TD between the 19th and 4th tray for the controller TDC1 in the prefractionator. L2 and L3 are adopted to regulate the TD between the 50th and 33rd tray, and TD between the 84th and 68th tray. This formation is established according to the separation systems. The main section performs adjacent component sharp splits, so the controlled sensitive temperatures indicate the product compositions relatively properly. However, the sharp splits carried out in the middle section $(\mathrm{A} / \mathrm{C}$ and $\mathrm{B} / \mathrm{D})$ and prefractionator $(\mathrm{A} / \mathrm{D})$ are not between adjacent components; besides, distributed components exist at both top and bottom streams of the middle section and prefractionator. Therefore, the controlled sensitive temperatures indicate the product compositions relatively improperly, and the temperature difference controllers are more appropriate in the prefractionator and middle section. In summary, there are three temperature difference controllers in the prefractionator and the middle section and three temperature controllers in the main section in the STDC scheme. The controller values of the STDC scheme are also illustrated in Table 1.

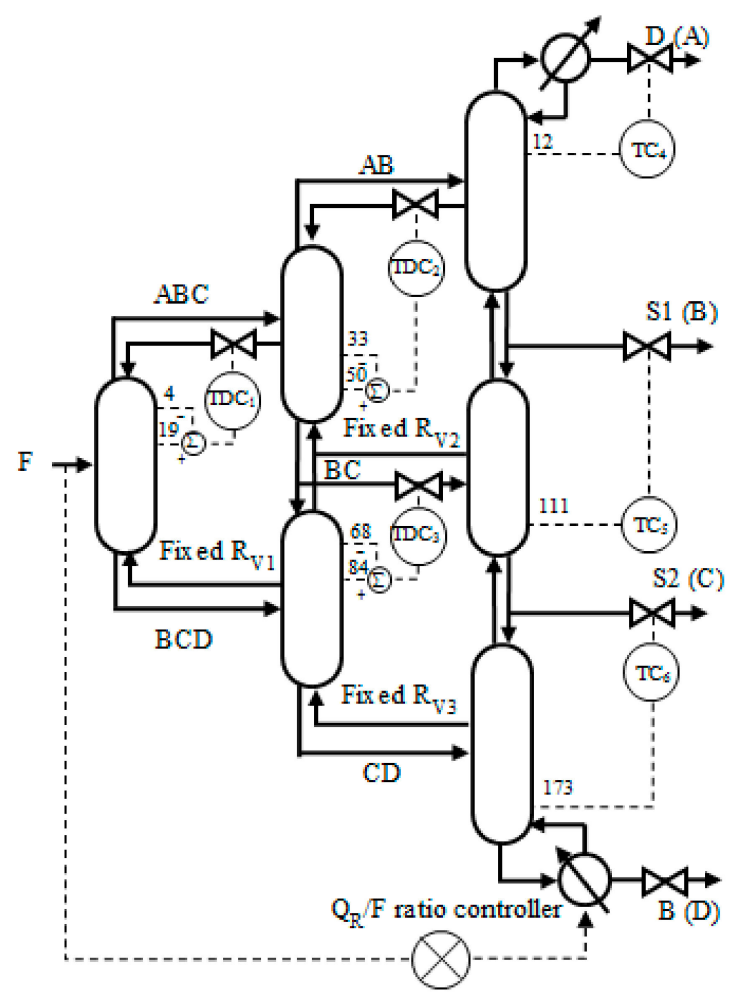

Figure 8. Simplified temperature difference control scheme (STDC).

\subsection{Simplified Double Temperature Difference Control Scheme (SDTDC)}

The SDTDC scheme, as illustrated in Figure 9, is introduced to further improve the dynamic performances using DTDC in the prefractionator and the middle section.

In the SDTDC scheme, DTDC is adopted in the middle section and prefractionator, while TC is implemented in the main section according to whether the separation systems are adjacent component sharp splits. Therefore, the difference between the SDTDC scheme and TC scheme is in the middle section and prefractionator. L1 is employed as the manipulated variable for the double temperature 
difference controller DTDC1. The controlled variable of the controller DTDC1 is the double temperature difference $\left[\left(\mathrm{T}_{\mathrm{P}, 19}-\mathrm{T}_{\mathrm{P}, 4}\right)-\left(\mathrm{T}_{\mathrm{P}, 4}-\mathrm{T}_{\mathrm{P}, 2}\right)\right]$ in the prefractionator. $\mathrm{L} 2$ and $\mathrm{L} 3$ are adopted to control double the temperature difference $\left[\left(\mathrm{T}_{\mathrm{MI}, 50}-\mathrm{T}_{\mathrm{MI}, 33}\right)-\left(\mathrm{T}_{\mathrm{MI}, 33}-\mathrm{T}_{\mathrm{MI}, 2}\right),\left(\mathrm{T}_{\mathrm{MI}, 84}-\mathrm{T}_{\mathrm{MI}, 68}\right)-\left(\mathrm{T}_{\mathrm{MI}, 68}-\mathrm{T}_{\mathrm{MI}, 50}\right)\right]$ in the middle section. In summary, there are three double temperature difference controllers in the prefractionator and the middle section and three temperature controllers in the main section in the SDTDC scheme. The controller values of the SDTDC scheme are illustrated in Table 1.

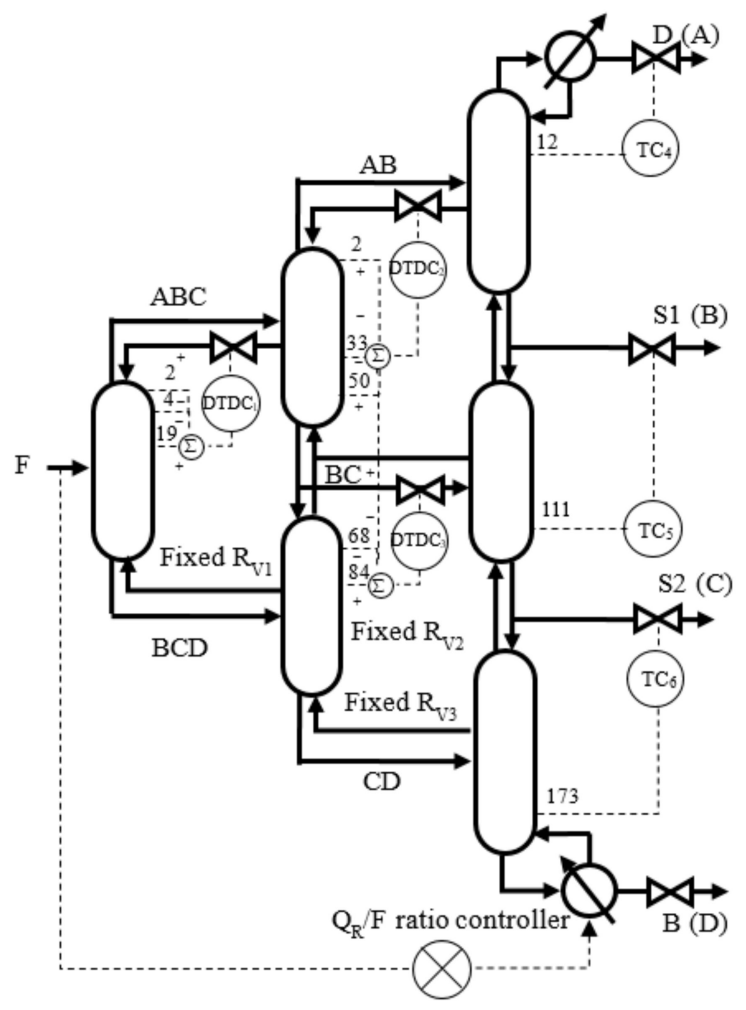

Figure 9. Simplified double temperature difference control scheme (SDTDC).

\section{Dynamic Performances and Discussions}

Dynamic performances of the four-product streams in face of $\pm 10 \%$ feed composition disturbances of A, B, C, and D inserted at $0.5 \mathrm{~h}$ are illustrated in Figure 10. The y axes represent the component compositions in the corresponding products. The $\mathrm{x}$ axes represent the response time. The dynamic performances of the four-product compositions when $\pm 10 \%$ feed flow rate disturbances inserted at $0.5 \mathrm{~h}$ are illustrated in Figure 11. The positive and negative responses are illustrated by black curves and gray curves, respectively. The dotted lines indicate the dynamic performances adopting the TC scheme, the dashed lines represent the dynamic performances using the STDC scheme, and the solid lines show the dynamic performances employing the SDTDC scheme.

Dynamic performances using the STDC scheme are mostly superior to those adopting the TC scheme. For the top and bottom products, the performances of the STDC scheme are slightly better than the performances of the TC scheme in most cases. For the first and second side product streams, the performances of the STDC scheme are considerably better than the performances of the TC scheme, especially in face of feed flow rate disturbances. When $\pm 10 \%$ flow rate disturbances occur, the STDC scheme is much better in maintaining the product purities and reducing the maximum deviations than the TC scheme. As for the settling time, the STDC scheme is also slightly superior to the TC scheme in most cases. The dynamic performances employing the SDTDC scheme are mostly superior to those adopting the TC scheme. For the top and bottom products, the performances employing the SDTDC scheme are slightly better than the performances adopting the TC scheme in most cases. For the first and second side product streams, the performances of the SDTDC scheme are much better than the 
performances of the TC scheme. In particular, the deviations employing the SDTDC scheme are mostly smaller compared with those employing the TC scheme.
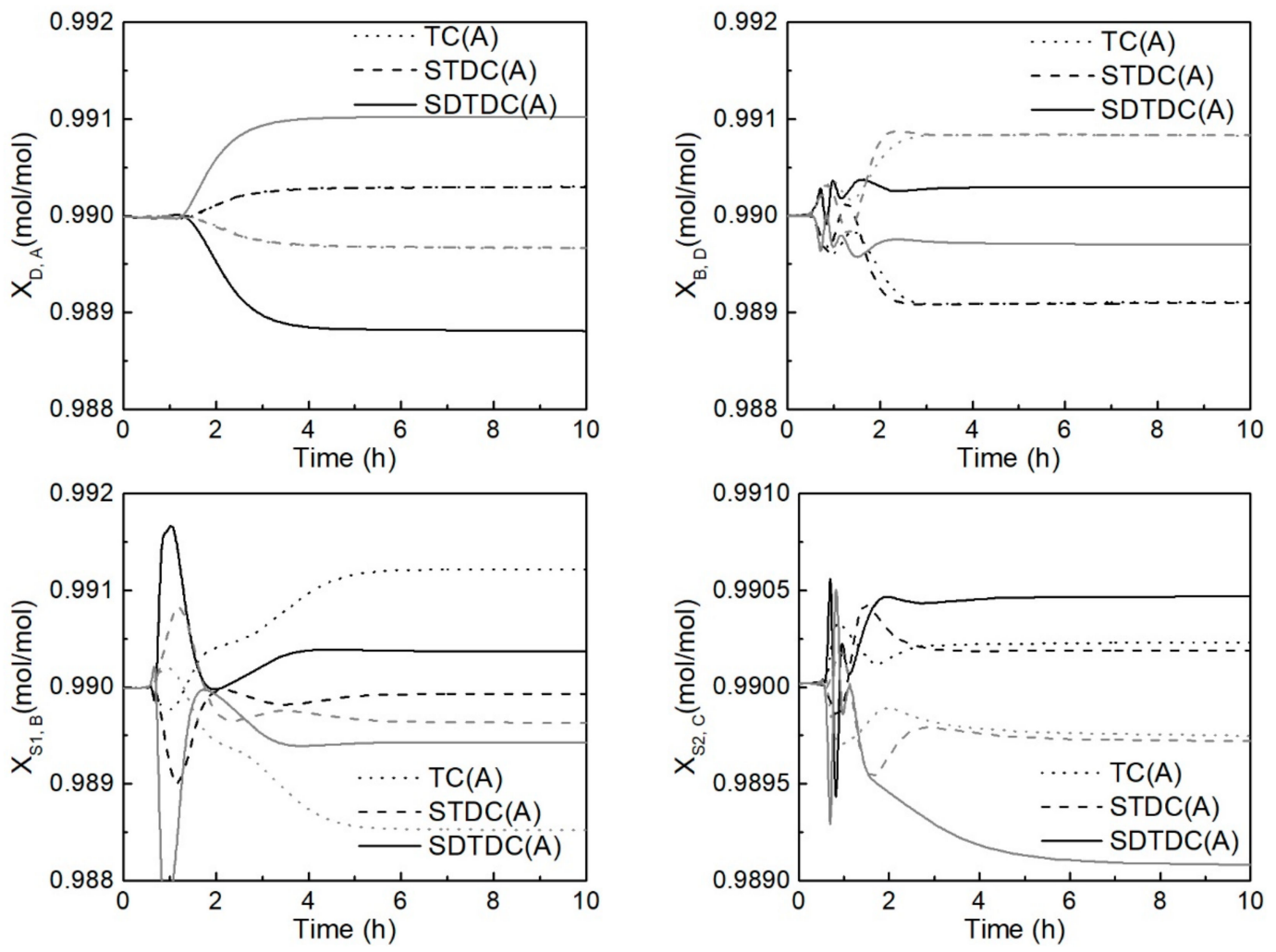

(a) A disturbances
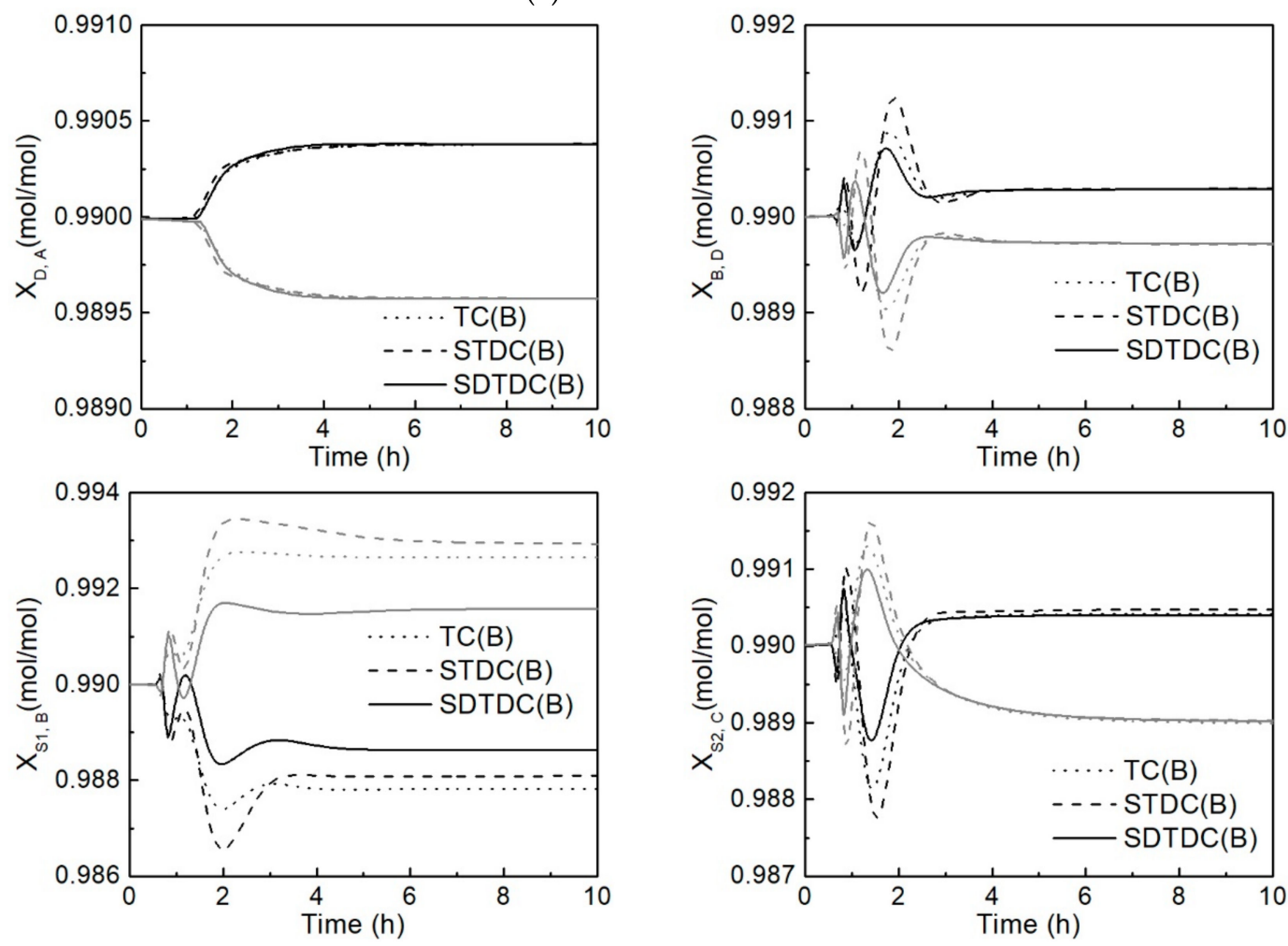

(b) B disturbances

Figure 10. Cont. 

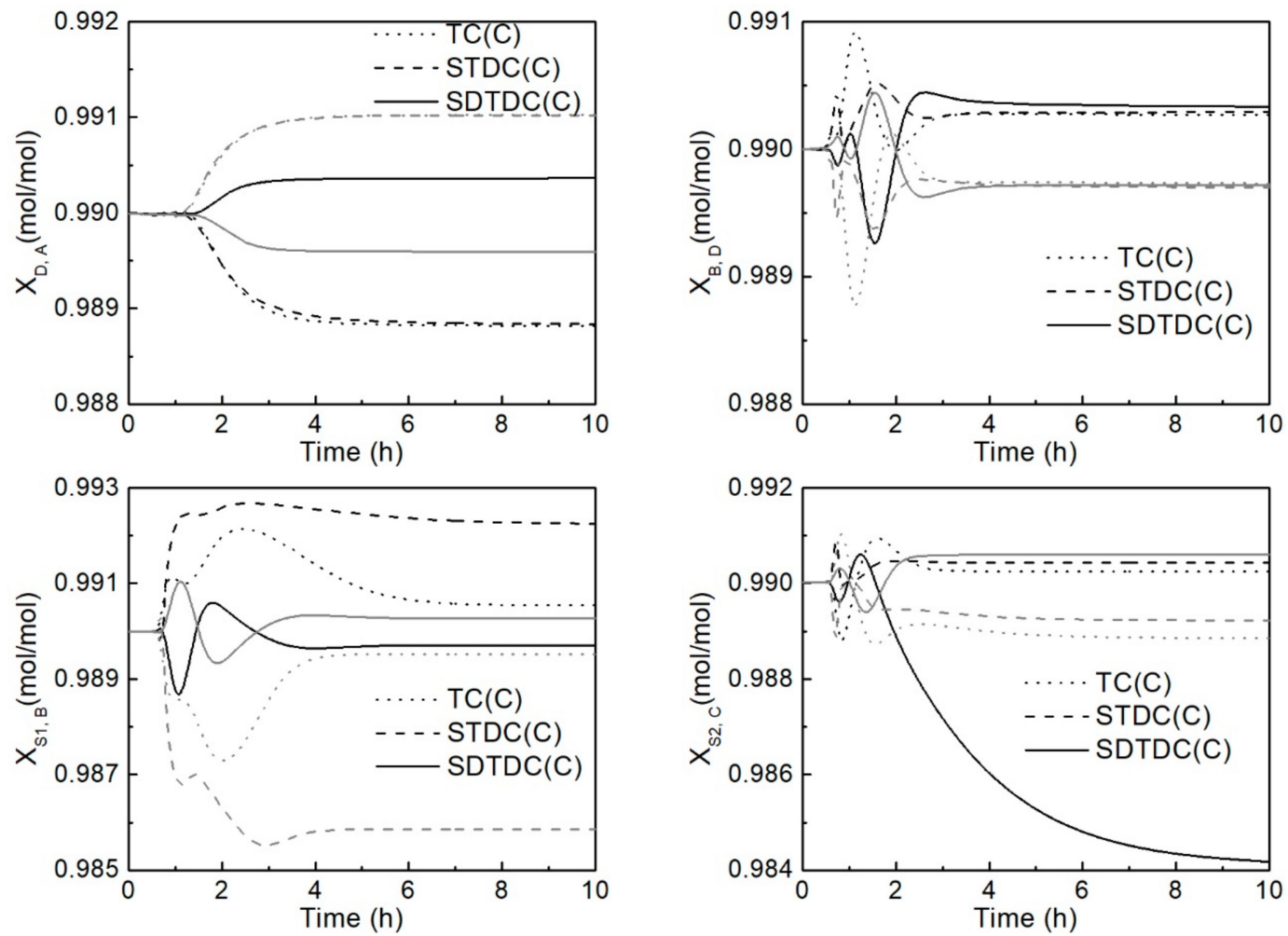

(c) C disturbances
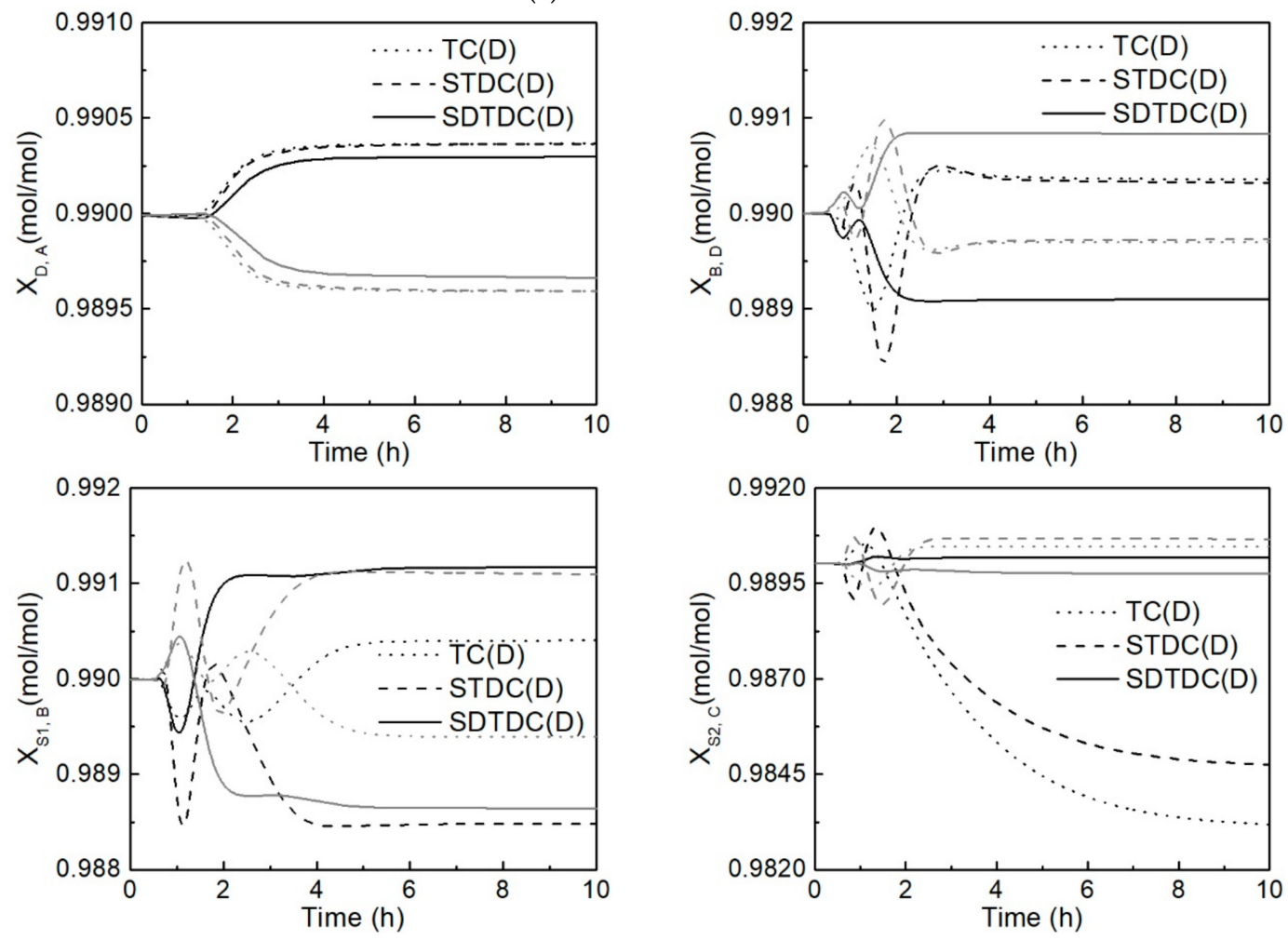

(d) D disturbances

Figure 10. Dynamic responses in face of $\pm 10 \%$ feed composition disturbances. 

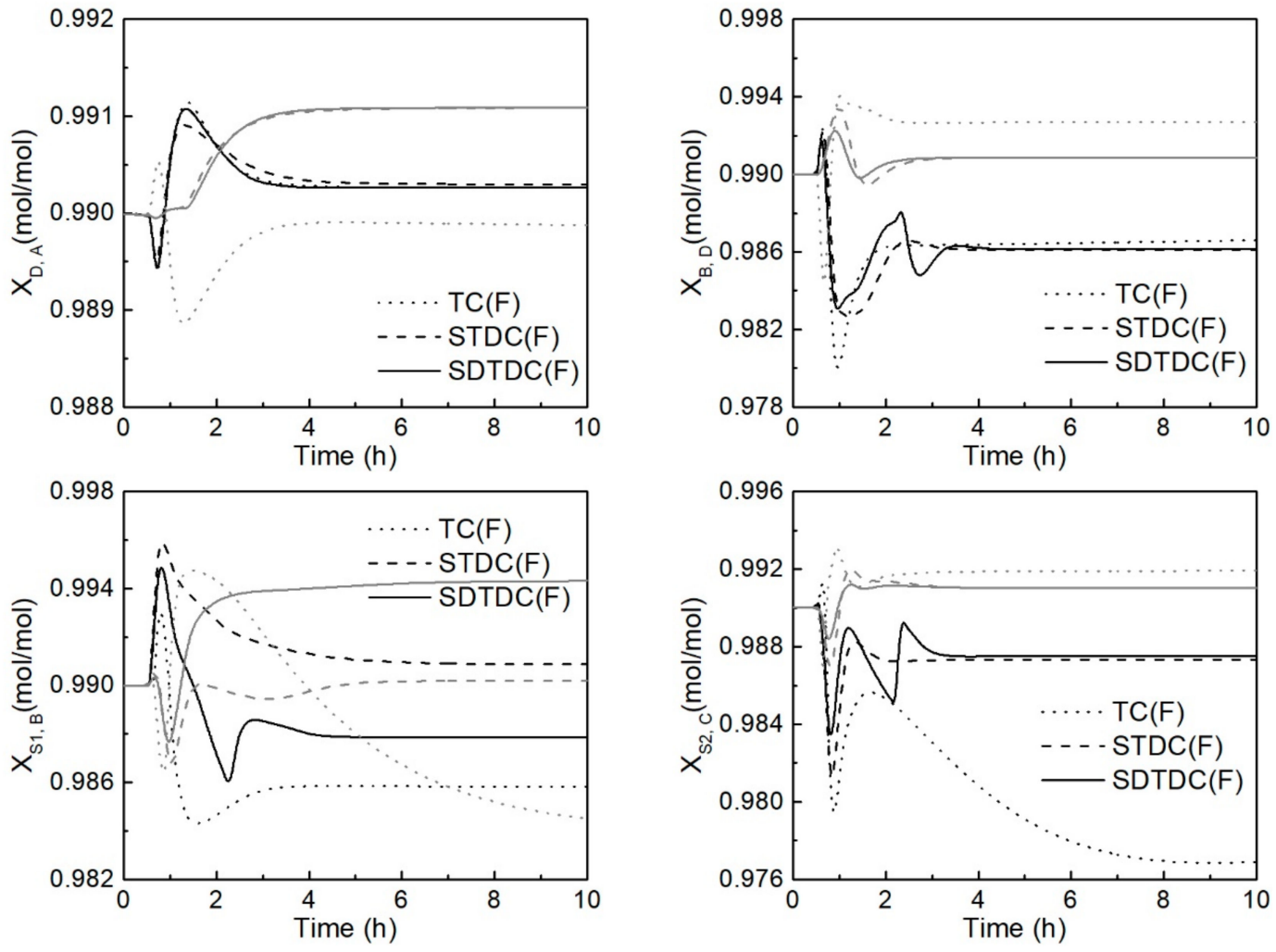

Figure 11. Dynamic responses in face of $\pm 10 \%$ feed flow disturbances.

Therefore, although the STDC and SDTDC schemes require more temperature sensors than the TC scheme, they are better choices considering the settling time, the steady-state, and maximum deviations. Besides, the STDC and SDTDC schemes with pure temperature sensors are feasible for the complicated four-product extended Petlyuk DWDC, which is an encouraging result for its industrialization. Experimental and industrial verification is able to be performed in the future based on the simulation results.

\section{Conclusions}

Three control schemes containing temperature control scheme (TC), simplified temperature difference control scheme (STDC), and simplified double temperature difference control scheme (SDTDC) are proposed for the extended Petlyuk DWDC. The proposed schemes are tested against a series of feed compositions and feed flow disturbances. One TC/TDC loop is adopted to separate one sharp split for the four-product extended Petlyuk DWDC. The prefractionator completes one sharp split, so the prefractionator requires one TC/TDC controller. The middle section accomplishes two sharp splits, therefore it requires two TC/TDC controllers. The main section carries out three sharp splits, therefore it requires three TC/TDC controllers. In summary, six TC/TDC controllers are needed at least to regulate the four-product extended Petlyuk DWDC. There are adjacent component sharp splits in the main section, so the controlled sensitive temperatures indicate the product compositions relatively properly. However, the sharp splits in the middle section and prefractionator are not between adjacent components; besides, distributed components exist at both top and bottom streams of the middle section and prefractionator. Therefore, the controlled sensitive temperatures indicate the product compositions relatively improperly, and the temperature difference controllers are more appropriate in the prefractionator and the middle section. Dynamic performances prove that the STDC and SDTDC schemes are better choices considering the settling time, the steady-state deviations, and the maximum deviations. Pure temperature control (without composition control) is applied in this paper so as to be more applicable in industries. The vapor splits are also fixed so as to be more applicable in 
industries. In summary, the STDC and SDTDC schemes with pure temperature sensors are feasible for the complicated four-product extended Petlyuk DWDC. These are very encouraging results for large-scale industrialization of the four-product extended Petlyuk DWDC in the future.

Author Contributions: Formal analysis, X.Q.; investigation, X.Q. and R.L.; methodology, X.Q.; project administration, X.Q., K.H., H.C., Y.Y., and L.Z.; software, X.Q.; supervision, K.H.; writing-original draft preparation, X.Q. and R.L.; writing-review and editing, K.H., H.C., Y.Y., L.Z., and S.W. All authors have read and agreed to the published version of the manuscript.

Funding: This research was funded by the National Nature Science Foundation of China (grant numbers: 21808007, 21878011, 21676011, 21576014), the Open Foundation of State Key Laboratory of Chemical Engineering (grant number: SKL-ChE-18B01), the China Postdoctoral Science Foundation (grant numbers: 2017M620587, 2019M650453), and the Fundamental Research Funds for the Central Universities (grant numbers: ZY1837, ZY1930).

Conflicts of Interest: The authors declare no conflicts of interest. The funders had no role in the design of the study; in the collection, analyses, or interpretation of data; in the writing of the manuscript; or in the decision to publish the results.

\section{References}

1. Kiss, A.A. Distillation technology-still young and full of breakthrough opportunities. J. Chem. Technol. Biotechnol. 2014, 89, 479-498. [CrossRef]

2. Dejanovic, I.; Matijasevic, L.; Olujic, Z. Dividing wall column-A breakthrough towards sustainable distilling. Chem. Eng. Process. 2010, 49, 559-580. [CrossRef]

3. Triantafyllou, C.; Smith, R. The design and optimisation of fully thermally coupled distillation columns: Process design. Chem. Eng. Res. Des. 1992, 70, 118-132.

4. Dejanovic, I.; Matijasevic, L.; Halvorsen, I.J.; Skogestad, S.; Jansen, H.; Kaibel, B.; Olujic, Z. Designing four-product dividing wall columns for separation of a multicomponent aromatics mixture. Chem. Eng. Res. Des. 2011, 89, 1155-1167. [CrossRef]

5. Wolff, E.A.; Skogestad, S. Operation of integrated three-product (Petlyuk) distillation columns. Ind. Eng. Chem. Res. 1995, 34, 2094-2103. [CrossRef]

6. Wang, S.J.; Wong, D.S.H. Controllability and energy efficiency of a high-purity divided wall column. Chem. Eng. Sci. 2007, 62, 1010-1025. [CrossRef]

7. Ling, H.; Luyben, W.L. New control structure for divided-wall columns. Ind. Eng. Chem. Res. 2009, 48, 6034-6049. [CrossRef]

8. Ling, H.; Luyben, W.L. Temperature control of the BTX divided-wall column. Ind. Eng. Chem. Res. 2010, 49, 189-203. [CrossRef]

9. Dwivedi, D.; Halvorsen, I.J.; Skogestad, S. Control structure selection for three-product Petlyuk (dividing wall) column. Chem. Eng. Process. 2013, 64, 57-67. [CrossRef]

10. Dwivedi, D.; Halvorsen, I.J.; Skogestad, S. Control structure selection for four-product Petlyuk column. Chem. Eng. Process. 2013, 67, 49-59. [CrossRef]

11. Fan, G.; Jiang, W.; Qian, X. Comparison of stabilizing control structures for four-product Kaibel column. Chem. Eng. Res. Des. 2016, 109, 675-685. [CrossRef]

12. Qian, X.; Huang, K.; Jia, S.; Chen, H.; Yuan, Y.; Zhang, L.; Wang, S. Composition/temperature cascade control for a Kaibel dividing wall distillation column by combining PI controllers and model predictive control integrated with soft sensor. Comput. Chem. Eng. 2019, 126, 292-303. [CrossRef]

13. Luyben, W.L. Distillation Design and Control Using Aspen Simulation; John Wiley \& Sons: New York, NY, USA, 2013.

14. Skogestad, S. The dos and don'ts of distillation column control. Chem. Eng. Res. Des. 2007, 85, 13-23. [CrossRef]

15. Yu, C.C.; Luyben, W.L. Use of multiple temperatures for the control of multicomponent distillation columns. Ind. Eng. Chem. Process Des. Dev. 1984, 23, 590-597. [CrossRef]

(C) 2020 by the authors. Licensee MDPI, Basel, Switzerland. This article is an open access article distributed under the terms and conditions of the Creative Commons Attribution (CC BY) license (http://creativecommons.org/licenses/by/4.0/). 